\title{
Functionalised microwave sensors for real-time monitoring of copper and zinc concentration in mining-impacted water
}

\author{
I. Frau $^{1}$ (D) S. R. Wylie ${ }^{1}$ (D) P. Byrne ${ }^{2}$ (D) J. D. Cullen ${ }^{1}$ (D) O. Korostynska ${ }^{3}$ - A. Mason ${ }^{1,4,5}$ (D)
}

Received: 11 June 2019 / Revised: 25 October 2019 / Accepted: 11 November 2019 / Published online: 16 November 2019

(C) The Author(s) 2019

\begin{abstract}
Microwave spectroscopy has been identified as a novel and inexpensive method for the monitoring of water pollutants. Integrating microwave sensors with developed coatings is a novel strategy to make the sensing system more specific for a target contaminant. This study describes the determination of copper and zinc concentration in water in both laboratoryprepared and acquired mine water samples from two abandoned mining areas in Wales, UK. Uncoated sensors immersed in samples spiked with $1.25 \mathrm{mg} / \mathrm{L}$ concentrations of copper and zinc, using the standard addition method, were able to quantify the concentration at $0.44 \mathrm{GHz}$ with a strong linear correlation $\left(R^{2}=0.99\right)$ for the reflection coefficient magnitude $\left(\left|\mathrm{S}_{11}\right|\right)$. Functionalised microwave sensors with L-cysteine, chitosan and bismuth zinc cobalt oxide-based coatings have shown improvement in the sensing performance. Specifically, the linear correlation at $0.91-1.00 \mathrm{GHz}$ between $\left|\mathrm{S}_{11}\right|$ and a polluted water sample spiked with $\mathrm{Cu}$ showed a higher $\left(R^{2}=0.98\right)$, sensitivity $(1.65 \Delta \mathrm{dB} / \mathrm{mg} / \mathrm{L})$ and quality factor (135) compared with uncoated sensors $\left(R^{2}=0.88\right.$, sensitivity of $0.82 \Delta \mathrm{dB} / \mathrm{mg} / \mathrm{L}$ and Q-factor 30.7). A Lorentzian peak fitting function was applied for performing advanced multiple peak analysis and identifying the changes in the resonant frequency peaks which are related to the change in metal ion content. This novel sensor platform offers the possibility of in situ monitoring of toxic metal concentrations in mining-impacted water, and multiple peak features, such as area, full width half maximum, centre and height of the peaks, have the possibility to offer higher specificity for similar toxic metals, as between copper and zinc ions.
\end{abstract}

Keywords Planar electromagnetic sensors $\cdot$ Coatings $\cdot$ Standard addition method $\cdot$ Chelating polymers $\cdot$ Lorentzian peak curve fitting $\cdot$ Heavy metals

Editorial responsibility: M. Abbaspour.

I. Frau

i.frau@2016.ljmu.ac.uk; 88ilariafrau@gmail.com

1 Faculty of Engineering and Technology, Built Environment and Sustainable Technologies (BEST) Research Institute, Liverpool John Moores University, B01, James Parsons Building, Byrom Street, Liverpool L3 3AF, UK

2 Faculty of Science, School of Natural Sciences and Psychology, Liverpool John Moores University, Liverpool L3 3AF, UK

3 Faculty of Technology, Art and Design, Department of Mechanical, Electronic and Chemical Engineering, Oslo Metropolitan University, Oslo, Norway

4 Animalia AS, Norwegian Meat and Poultry Research Centre, PO Box 396, 0513 Økern, Oslo, Norway

5 Faculty of Science and Technology, Norwegian University of Life Sciences, 1432 Ås, Norway

\section{Introduction}

\section{Metal pollution and monitoring challenges}

Mining is an important contributor to global wealth (Younger et al. 2002). However, metal and mineral extraction generates huge quantities of waste rich in potentially toxic elements, including metals, that can impact the ecosystem and human health (Byrne et al. 2018; Wolkersdorfer 2008). The major mechanisms associated with the mobilisation of metal ions in mining areas are: (i) the oxidation and consequent hydrolysis of sulphide minerals in mine waters (Johnson 2003), (ii) the leaching from deposits of mine tailings (Perkins et al. 2016) and (iii) fluvial transport of mobilised metals from headwater catchments to coastal areas (Mayes et al. 2013).

Copper $(\mathrm{Cu})$ and zinc $(\mathrm{Zn})$ are among the most common toxic elements associated with mine wastes and have been widely documented to cause significant pollution of water 
resources (Environment Agency 2008). They are essential elements for living organisms, but high concentrations, especially with long-term exposure, can generate significant health problems, such as respiratory, gastrointestinal and neuronal disorders (Agency for Toxic Substances and Disease Registry (ATSDR) 2004). For this reason, the EU Water Framework Directive (EU WFD) and the US Environmental Protection Agency (US EPA) have developed environmental quality standards (EQS) that specify that the concentration of dissolved $\mathrm{Cu}$ and $\mathrm{Zn}$ in freshwater should not exceed $28-34 \mu \mathrm{g} / \mathrm{L}$ and $125-210 \mu \mathrm{g} / \mathrm{L}$, respectively (UK Technical Advisory Group on the Water Framework Directive 2008; United States Environmental Protection Agency 1986). Globally, $\mathrm{Cu}$ and $\mathrm{Zn}$ concentrations in mine water range from $<0.01$ to $10 \mathrm{mg} / \mathrm{L}$ (Byrne et al. 2012). In the UK, 9\% of rivers in England and Wales are at risk of exceeding this threshold (Environment Agency 2008). For instance, Parys Mountain copper mine, in Anglesey, is the single largest contributor of $\mathrm{Cu}$ to the Irish Sea, with $\mathrm{Cu}$ concentrations in excess of 3-20 mg/L (Dean et al. 2013). Thousands of abandoned mining areas need to be monitored in more detail for better prioritisation of effective remedial actions (Environment Agency 2012).

The current standard methods for quantifying the concentration of toxic metals in water are laboratory-based and involve collected samples being analysed by inductively coupled plasma optical emission spectrometry (ICPOES), inductively coupled plasma mass spectroscopy (ICP-MS), atomic absorption spectroscopy (AAS) and neutron activation analysis (NAA) (Bansod et al. 2017). Although these techniques are highly sensitive and versatile in terms of the simultaneous determination of multielements in complex matrices, they are not able to provide in situ, real-time and low-cost metal concentration data required by regulators and mining companies to monitor and protect water resources (Shukla et al. 2018).

There have been major advancements recently in technologies for in situ metal concentration monitoring, mostly based on the following technologies: voltammetry (Holmes et al. 2018; Wu et al. 2019), aptasensors (Varun and Daniel 2018), near infrared (Iqbal et al. 2017), fluorescence and colorimetric (Guo et al. 2019; Tan et al. 2016), colorimetric microfluidic (Xie et al. 2019), optical fibre-based sensors (Kopitzke and Geissinger 2014). Among existing commercial anodic stripping voltammetry (ASV)-based analysers, there are PDV6000ultra and Metalyser ${ }^{\circledR}$ Portable HM1000, developed by $\operatorname{Trace}_{2} \mathrm{O}$ and Modern Water, respectively, that offers portability, multimetal detection and relative fast measurement time (Barton et al. 2016). However, they require sample collection and pre-concentration, so they are not able to detect toxic metals in water directly for in situ measurements (Holmes et al. 2018). Consequently, they cannot be installed as part of a remote monitoring system (Cases-Utrera et al. 2015).

One of the biggest challenges is therefore to develop novel technologies able to detect toxic metals continuously to minimise the impact of mining by increasing the scientific understanding of transport processes and by providing early warning of pollution episodes (National Academies of Sciences and Medicine 2018).

\section{Microwave technology and water}

Microwave spectroscopy has emerged in recent years as a novel monitoring technique in the food industry (Mason et al. 2016), healthcare (Wang 2018), sports science (Greene et al. 2019), structural analysis (Zarifi et al. 2018a) and water quality control (Korostynska et al. 2014). This wide range of applications is due to the adaptability of the sensing structure, which can include resonant cavities, horn antennas, transmission lines, waveguides, flexible and planar resonant sensors, depending on the form of the material under test (MUT).

Current research has demonstrated the possibility to determine the presence and concentration of specific components and pollutants in water, e.g. lead ions $\left(\mathrm{Pb}^{2+}\right)($ Frau et al. 2018a), sugars (Harnsoongnoen et al. 2018), nitrates (Cashman et al. 2017), phosphate (Nag et al. 2019), antibiotics (Mason et al. 2018), silver materials (Ateeq et al. 2017), water in fuel (Andria et al. 2019), marine algae (Moejes et al. 2018), liquid mixtures, as acetone and water (Wei et al. 2018), ethanol and water (Salim et al. 2018; Wiltshire and Zarifi 2018).

The detection principle is based on the rotation and polarisation of the water molecules and other chemical compounds when an electromagnetic field is applied to a sample under test through a sensing structure. The reflected microwave signal varies with frequency due to the interaction of the electric field with the MUT because its conductivity and permittivity are frequency dependent. The electrical conductivity is the material's ability to conduct a current, while the permittivity is a measure of how an electric field affects a dielectric medium. The permittivity $(\varepsilon)$ is a complex value characterised by a real $\left(\varepsilon^{\prime}\right)$ and an imaginary $\left(\varepsilon^{\prime \prime}\right)$ component (Korostynska et al. 2013). $\varepsilon^{\prime}$ depends on how electrical energy is stored by the material, while $\varepsilon$ " represents how this energy can be dissipated as heat (Jilani et al. 2012). The electromagnetic sensors output can be presented in terms of S-parameters. Measurements for a one-port configuration (e.g. reflection coefficient magnitude, as $\left|S_{11}\right|$ ) provide a spectral response that depends on the composition and concentration of the MUT.

Some of the advantages of this technique compared with optical and electrochemical methods are (i) the immediate measurement response when a water sample is in contact 
with the EM field; (ii) its noninvasiveness, considering this is a field-propagation-based technique (Kölbl et al. 2018); (iii) its low power $(1 \mathrm{~mW})$ and measurement costs. Some of the disadvantages are related to the capability to detect every minor change in the MUT measurement, such as temperature and density (Al-Kizwini et al. 2013). Consequently, researching the causes of every change and assessing how to correct for them are fundamental steps for the application of this technology in the real world.

Between the numerous possible resonant structures, planar sensors have the potential to give high sensitivity and accuracy (Rahman et al. 2017). Moreover, they have the advantages of small size (from $\mathrm{mm}$ to $\mathrm{cm}$ ), robustness and low-price fabrication. They are portable, light and practical for in situ and continuous monitoring, compared with resonant cavities and can be easily implemented with materials, as thin and thick films, microfluidic structures, etc. (Zarifi and Daneshmand 2016).

\section{F-EM sensors}

For a sensing platform to deliver high sensitivity (to detect low $\mathrm{Cu}$ concentration) and selectivity (to distinguish between similar metal ions), the integration of interface materials on planar sensors, such as polymers, nanotube, nanoparticles, nanorods, metamaterials, biomaterials, is a novel, attractive approach for microwave and impedance spectroscopy (Azmi et al. 2017; Ebrahimi et al. 2014; Zarifi et al. 2018b). The addition of materials on the sensing surfaces has been recognised as being able to improve resolution and specificity (Chen et al. 2012).

These functionalised electromagnetic (f-EM) sensors determine a more specific response thanks to the particular chemical or physical interactions between the materials and the target analyte under test. Screen-printing technology can be used to place thick films on planar EM sensors. The produced coatings have the advantage of being repeatable, reusable and can be prepared using a mixture of various materials, increasing the specific detection of compounds in complex water matrices (Frau et al. 2019b).

Polymers are able to improve the specificity, especially integrated with metal oxides (Graunke et al. 2018). Chelating polymers are able to interact with $\mathrm{Cu}$ ions, thanks to their hydroxyl and amine groups, which are reactive to $\mathrm{Cu}$ ions (Koneswaran and Narayanaswamy 2009; Ngah and Fatinathan 2008). Metal oxides have high surface area, reactive sites and are able to adsorb toxic metals (Ugwu and Igbokwe 2019).

The aims of this paper are: (1) to demonstrate the feasibility of using microwave spectroscopy to quantify changes in $\mathrm{Cu}$ and $\mathrm{Zn}$ concentration in water using the standard addition method; (2) to evaluate the sensitivity for $\mathrm{Cu}$ ion concentration using the f-EM sensors based on mixtures of $\mathrm{L}$-cysteine, chitosan and bismuth cobalt zinc oxide; (3) to evaluate the selectivity for $\mathrm{Cu}$ and $\mathrm{Zn}$ as changes in spectral responses by applying a Lorentzian peak fitting function for multiple parameter peak analysis; (4) to measure mining-impacted water samples collected in stream water in the UK.

To achieve the investigation aims, this novel research was carried out between May 2018 and June 2019 in the engineering and chemical laboratories at Liverpool John Moores University (Liverpool, UK), where f-EM sensors and samples were prepared. Polluted samples were acquired from two mining areas in Wales (UK) during July 2018. These were then tested to evaluate the potential of this novel technology.

\section{Materials and methods}

\section{Thick film preparation}

In this work, 8-pair gold interdigitated electrodes (IDE) printed on PTFE substrates (Fig. 1a) were functionalised using a semi-automatic screen printer (Super Primex) as described by Frau et al. (2018b) with a paste mixture based on L-cysteine (168149 Sigma-Aldrich, 40\%), chitosan (448869 Sigma-Aldrich, 40\%) and bismuth cobalt zinc oxide (631930 Sigma-Aldrich, 10\%) (acronym: L-CyChBCZ). These materials, in powder form, were mixed with $7.7 \%$ of a binder, Butvar ${ }^{\circledR}$ B-98 (solid form, B0154 Sigma-Aldrich), and an adequate amount of a solvent, ethylene glycol butyl ether (liquid form, 579556 Sigma-Aldrich), to achieve the correct viscosity for screen printing ( 0.1 to $10 \mathrm{~Pa} \mathrm{~s}$ ) (Prudenziati and Hormadaly 2012). Of the different paste mixtures tested, this was found to be the most promising for detecting toxic metals in water.

The f-EM sensors (Fig. 1b) were cured in an oven at $150{ }^{\circ} \mathrm{C}$ for $1 \mathrm{~h}$ between each of the 6 prints, before soldering

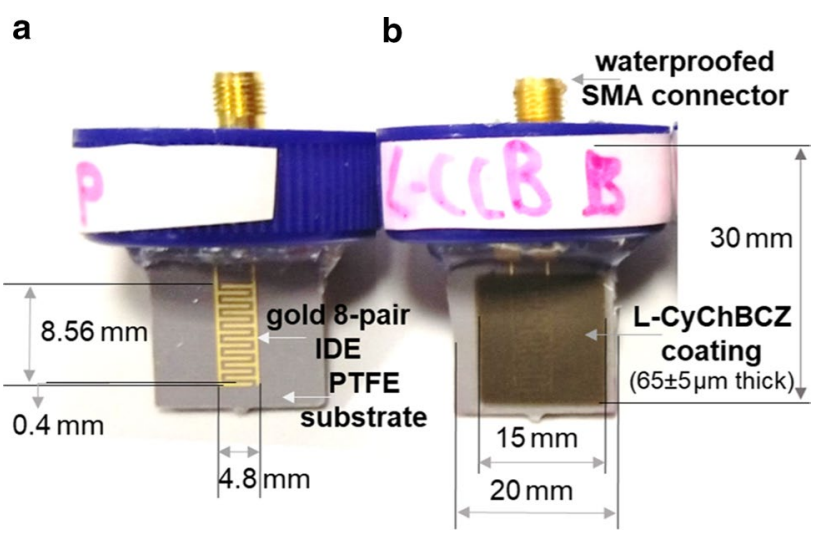

Fig. 1 a Uncoated gold 8-pair IDE sensors and b f-EM sensor based on L-CyChBCZ coating 
to an SMA connector. The final thickness of the film, measured using a surface profiler (Taylor Hobson, Form Talysurf 120 ), was $65 \pm 5 \mu \mathrm{m}$. The connectors were then waterproofed using a thermoplastic adhesive, consisting of ethylene-vinyl acetate (EVA) and terpene-phenol resin (TPR) (internal part), and silicone (external part) and embedded in $50-\mathrm{mL}$ centrifuge tube lids.

The coatings were characterised before and after their interaction with $\mathrm{Cu}$-contaminated water samples using a scanning electron microscope (SEM, model FEI, Quanta 200) and an energy-dispersive spectroscopy (EDS, model INCA-X-act, Oxford Instruments), connected to the SEM.

\section{Water sample preparation and collection}

$\mathrm{Cu}$ and $\mathrm{Zn}$ solutions were prepared using copper and zinc standards for ICP (68921 and 18562 Sigma-Aldrich, in 2\% nitric acid, prepared with high-purity $\mathrm{Cu}$ and $\mathrm{Zn}$ metal, $\mathrm{HNO}_{3}$ and water) by adding the required concentration in deionised water (DW). Simulated "unknown" samples with 3 (UNK3) and 0.2 (UNK0.2) mg/L of $\mathrm{Cu}$ and $\mathrm{Zn}$, respectively, were prepared. Then, they were spiked using the standard addition method (as described in section Adapted standard addition method) to quantify the concentration of the spiked $\mathrm{Cu}$ and $\mathrm{Zn}$ samples in DW.

Four polluted samples (Frongoch Adit, Mill Race, Nant Ceunant and Parys Mountain Adit; respective acronyms: FA, MR, NC, PM) from two mining-impacted areas in Central (Wemyss mine) and North Wales (Parys Mountain) were collected and analysed. Rivers draining both mine areas have well-documented water quality problems and fail to meet EQS for $\mathrm{Cu}$ (Parys Mountain) and Zn (Parys Mountain and Wemyss) (Dean et al. 2013; Onnis et al. 2018).

$\mathrm{Cu}$ and $\mathrm{Zn}$ concentrations for these samples were analysed using an inductively coupled plasma mass spectrometry (ICP-MS, model 7900 Agilent Technologies). Electrical conductivity (EC), $\mathrm{pH}$ and temperature were measured using a multiparameter metre (model PCE-PHD 1, PCE Instruments). Temperature was also constantly monitored using a digital and a noncontact infrared thermometer (model TM-902C Lutron and 830-T2 Testo, respectively), and the room was kept at a constant temperature of $20^{\circ} \mathrm{C}$.

\section{Reflection coefficient}

The reflection coefficient magnitude $\left(\left|S_{11}\right|\right)$ was measured between $10 \mathrm{MHz}$ and $3 \mathrm{GHz}$ using a vector network analyser (VNA), Rohde and Schwarz ZVA 24 VNA. Uncoated sensors (Fig. 2a) and f-EM sensors (Fig. 2b) were connected, through a coaxial cable (50 $\Omega$ impedance) and SMA connectors using a one-port configuration, to the VNA with the output power set at $0 \mathrm{dBm}$, and the waterproofed sensing structure was immersed in the water solutions. The EM response was recorded continuously, and each measurement was repeated 5 times. Experiments were performed in a temperature-controlled environment $\left(20^{\circ} \mathrm{C}\right)$ to minimise outside influences.

The sensing performances were evaluated by comparing responses between uncoated and coated sensors, analysing the $R^{2}$, the coefficient of variation $(\mathrm{CV}$, as the ratio of the standard deviation (SD) to the mean), the sensitivity for every $1 \mathrm{mg} / \mathrm{L}$ changes of $\mathrm{Cu}$, the quality factor of the peaks (Q-factor) and the limit of detection (LOD). The sensitivity is equivalent to the slope of the calibration curve attained as $\left|\mathrm{S}_{11}\right|$ versus $\mathrm{Cu}$ concentration (Rahman et al. 2018). The LOD was evaluated, as described by Salim and Lim (2018), using Eq. 1 which describes the smallest concentration of $\mathrm{Cu}$ that can be detected; the Q-factor is calculated using Eq. 2.

$\mathrm{LOD}=3.3 \times \frac{(\text { SD of blank response })}{(\text { slope of calibration curve })}$

$Q=\frac{f_{0}}{f_{3 \mathrm{~dB}}}$

where $f_{0}$ is the centre of the peak and $f_{3 \mathrm{~dB}}$ is the half-power bandwidth.
Fig. 2 a ZVA 24 connected through coaxial cables to an uncoated sensor and $\mathbf{b}$ an f-EM sensor based on L-CyChBCZ immersed in water for continuously monitoring the changes in $\mathrm{Cu}$ concentration
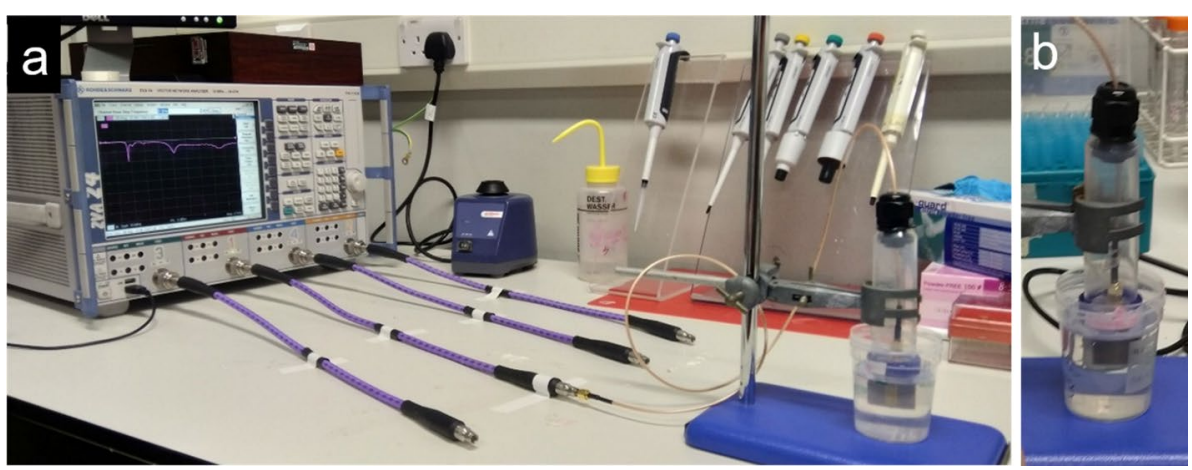


\section{Adapted standard addition method}

The standard addition method is a quantitative method for determining the concentration of an analyte in an unknown aqueous solution. The principle is based on the addition of the pollutant under test by multiple small and equal volumes to minimise the matrix effect which can interfere with the target analyte signal (Bader 1980). It is particularly important in the areas of instrumental methods, such as spectrophotometry, atomic absorption (AA) and electrochemistry, especially when complex matrices are analysed (Harris 2007). Using a linear calibration range, the response signal is directly proportional to the concentration (Bruce and Gill 1999). In this work, the standard addition method has been utilised with microwave spectroscopy for the first time.

The standard method was slightly modified, as the addition was performed continuously on the same sample, with the purpose of being able to evaluate the effective real-time change in the microwave responses related to the increase in the $\mathrm{Cu}$ content and to avoid small variations given by sample preparation. The change in $\left|S_{11}\right|$ response was monitored continuously. Once the resonant frequencies in the spectral response (between 0.01 and $3 \mathrm{GHz}$ ) were selected for $\mathrm{Cu}$ and $\mathrm{Zn}$, a calibration curve was produced by using the $\left|S_{11}\right|$ signal for the known quantities of the chemical of interest. The $\Delta \mathrm{S}_{11}$ of the blank response (the DW signal) was subtracted, and the linear regression was then plotted. The concentration of the unknown sample is determined using the slope and the intercept, which corresponds to the point at which the calibration plot crosses zero on the $\mathrm{x}$-axis.

Equation (3) was applied for each addition:

$\frac{C_{x}}{C_{x}+C_{s}}=\frac{\left|S_{11}\right|_{\text {for } x}}{\left|S_{11}\right|_{\text {for } x+s}}$

where $C_{x}$ and $C_{x}+C_{s}$ are, respectively, the concentrations of the pollutant without and with the standard addition, and $\left|S_{11}\right|_{\text {for } x}$ and $\left|S_{11}\right|_{\text {for } x+s}$ are the microwave signal of the solution alone and with the standard addition.

In this work, $40 \mathrm{~mL}$ of laboratory "unknown" samples, with concentrations of 3 (UNK3) and 0.2 (UNK0.2) $\mathrm{mg} / \mathrm{L}$ of $\mathrm{Cu}$ and $\mathrm{Zn}$, respectively, and an acquired sample (Frongoch Adit, FA) were spiked by adding $0.5 \mathrm{~mL}$ of $100 \mathrm{mg} / \mathrm{L} \mathrm{Cu}$ or $\mathrm{Zn}$ solution which corresponded to an increase of $1.25 \mathrm{mg} / \mathrm{L}$ in metal concentration. DW samples were also spiked likewise with $\mathrm{Cu}, \mathrm{Zn}$ and $\mathrm{Cu}+\mathrm{Zn}$ (1:1) solutions. Other samples (FA $+0.2 \mathrm{mg} / \mathrm{L}$ of $\mathrm{Cu}$ and $\mathrm{Zn}$ ) were prepared by dilution for measuring the decrease in concentration using the F-EM sensors.

\section{Signal analysis}

The spectral responses for the polluted water samples consist of a combination of peaks and troughs, both defined as peaks in this work. For more accurate identification of a specific metal in water sample under test, the full spectral response was analysed by fitting the $\left|S_{11}\right|$ responses using peak functions. This enabled the determination of multiple features for each individual peak, such as area, centre and height of the peaks. Moreover, if the spectral response is convoluted, with peaks which are superimposed upon one another, curve fitting is the best way to isolate peaks and define their specific characteristic (Meier 2005).

In the first instance, various $\mathrm{Cu}$ solutions were analysed and the $\left|\mathrm{S}_{11}\right|$ responses were fitted using symmetric profiles, such as Gaussian, Lorentzian and Voigtian (a convolution between them). The most accurate peak fitting results were achieved, as highlighted in bold in Table 1, with the Lorentzian function for both the $R^{2}$ and Chi-square, which represents the adherence of the moulded cumulative fit peak and the goodness of fit. Lorentzian peaks have a far wider tail than Gaussian ones, so are more representative to the peaks shapes obtained with microwave spectroscopy.

The Lorenz peak function used is given in Eq. (4):

$y=y_{0}+\frac{2 A}{\pi} \times \frac{w}{4\left(x-x_{\mathrm{c}}\right)^{2}+w^{2}}$

where $y_{0}$ is the offset; $x_{\mathrm{c}}$ is the centre of the peak; $w$ is the FWHM (full width at half maximum); and $A$ is the area of the peak.

Consequently, the $\left|S_{11}\right|$ responses for the tested samples were fitted with the Lorentzian peak fitting function and multiple peak analyses were performed.

\section{Results and discussion}

\section{Uncoated sensors and standard addition method}

The uncoated sensors were immersed in the $\mathrm{Cu}$ and $\mathrm{Zn}$ samples and measured using the ZVA 24. The microwave response was able to determine the change of the metal content, for both metals, with the same reflection coefficient at the same frequencies, considering the similarity of these

Table 1 Comparison of peak fitting function performances

\begin{tabular}{llll}
\hline & Gaussian & Lorentzian & Voigtian \\
\hline$R^{2}$ & $0.96 \pm 0.02$ & $\mathbf{0 . 9 9} \pm \mathbf{0 . 0 1}$ & $0.97 \pm 0.01$ \\
$\begin{array}{l}\text { Reduced Chi- } \\
\text { sqr. }\end{array}$ & $0.27 \pm 0.08$ & $\mathbf{0 . 0 6} \pm \mathbf{0 . 0 3}$ & $0.18 \pm 0.08$ \\
\hline
\end{tabular}


metals. The results are illustrated in Fig. 3, where the left column describes the $\mathrm{Cu}$ response $(\mathrm{a}, \mathrm{b}, \mathrm{c})$, and the right column the $\mathrm{Zn}$ response (d, e, f), for 3 and $0.2 \mathrm{mg} / \mathrm{L}$, respectively. Thus, the magnitude of the reflection coefficient $\left(\left|\mathrm{S}_{11}\right|\right)$ showed a linear correlation particularly in the three resonant peaks located at frequencies $<0.8 \mathrm{GHz}$, namely 0.01 , 0.44 and $0.76 \mathrm{GHz}$, as illustrated in Fig. $3 \mathrm{a}$ (for $\mathrm{Cu}$ ) and d (for $\mathrm{Zn}$ ). The peak located at $0.44 \mathrm{GHz}$ (Fig. $3 \mathrm{~b}$ and e) was selected and used for quantifying the actual concentration of the samples. This peak was selected for its higher linear correlation $\left(R^{2}>0.99\right)$, higher sensitivity $(0.485 \pm 0.003 \mathrm{~dB}$ for each $1 \mathrm{mg} / \mathrm{L}$ variation in $\mathrm{Cu}$ and $\mathrm{Zn}$ conc.) and low SD (RSD $<1 \%$ ) compared with the other two peaks.

Notably, the resonant peaks that were produced at frequencies $<0.5 \mathrm{GHz}$ have a lower $\mathrm{dB}$ as the metal concentration is increasing (the reflection decreases) compared
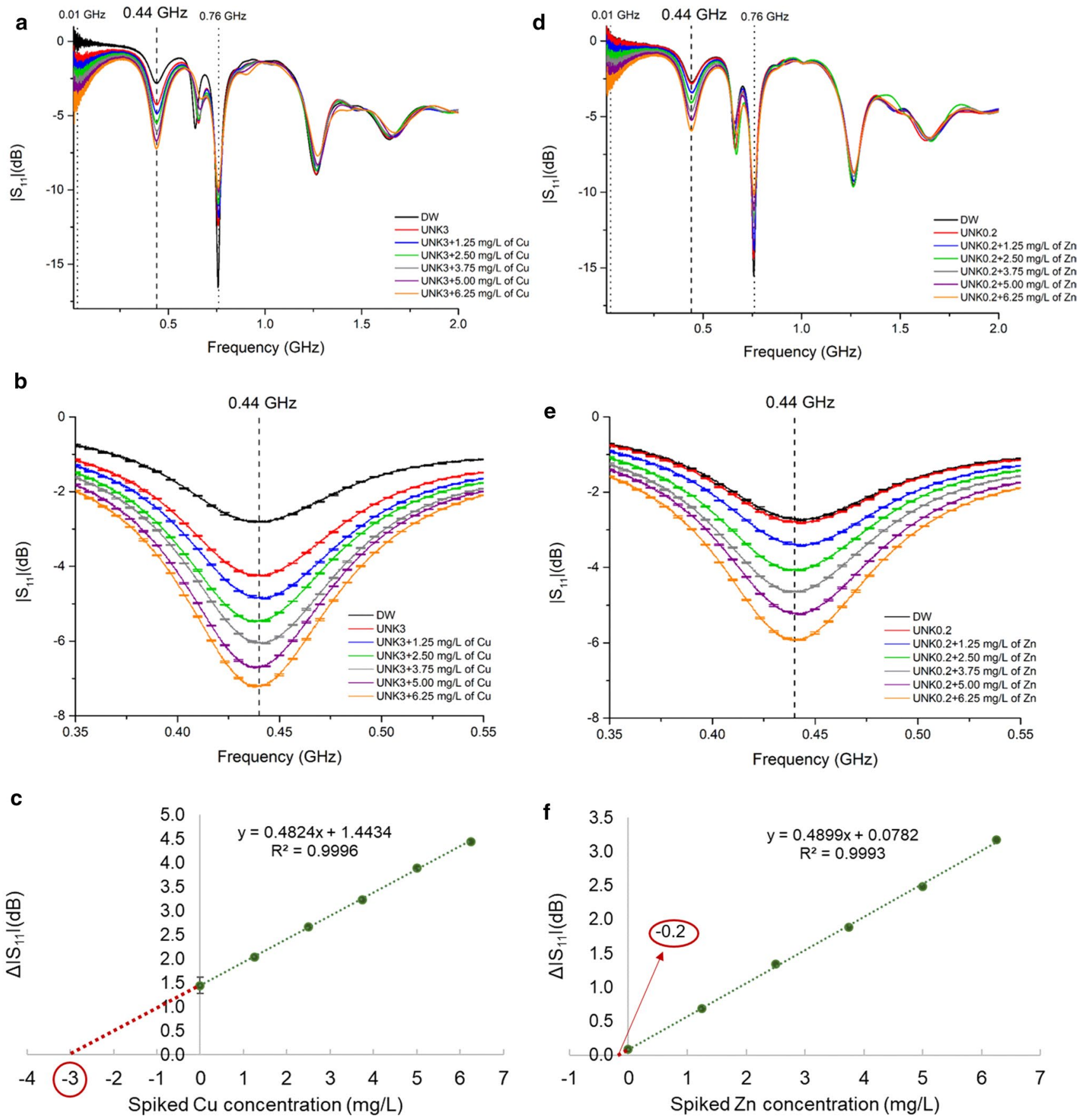

Fig. 3 a Spectral responses between 0.01 and $3 \mathrm{GHz}$ for "unknown" $\mathrm{Cu}$ (UNK3 as $3 \mathrm{mg} / \mathrm{L}$ ) solution, b magnification of the peak located at $440 \mathrm{MHz}$ and $\mathbf{c}$ its calibration plot; $\mathbf{d}, \mathbf{e}, \mathbf{f}$ are the equivalent three graphs for "unknown" $\mathrm{Zn}$ (UNK0.2 as $0.2 \mathrm{mg} / \mathrm{L}$ ) solution 
to the peaks at frequencies $>0.5 \mathrm{GHz}$, where inversely a higher $\mathrm{dB}$ is noticed as the concentration increases (the reflection increases), for both linear and polynomial correlations. For instance, the peak located at $0.44 \mathrm{GHz}$ is $-4.2 \mathrm{~dB}$ for $\mathrm{UNK} 3+1.25 \mathrm{mg} / \mathrm{L}$ of $\mathrm{Cu}$ and $-7.2 \mathrm{~dB}$ for $\mathrm{UNK} 3+6.25 \mathrm{mg} / \mathrm{L}$; at $0.76 \mathrm{GHz}$ the reflection coefficient is $-11.9 \mathrm{~dB}$ for $\mathrm{UNK} 3+1.25 \mathrm{mg} / \mathrm{L}$ of $\mathrm{Cu}$ and $-9.8 \mathrm{~dB}$ for $\mathrm{UNK} 3+6.25 \mathrm{mg} / \mathrm{L}$.

By plotting the linear correlation, the concentrations of $\mathrm{Cu}$ and $\mathrm{Zn}$ were determined, confirming the fact that microwaves are able to measure the concentration of $\mathrm{Cu}$ and $\mathrm{Zn}$ continuously using the reflection coefficient, $\left|S_{11}\right|$. This value corresponds to the $\mathrm{x}$-intercept of the linear correlation, resulting in $2.99 \mathrm{mg} / \mathrm{L}$ and $0.160 \mathrm{mg} / \mathrm{L}$ for $\mathrm{UNK} 3(\mathrm{Cu})$ and UNK0.2 (Zn) samples.

This study demonstrates the feasibility of the microwave response to detect the increase in metal content in water and to quantify its change. However, this experiment demonstrates the necessity of finding a solution for improving the specificity, as sensitivity and selectivity for metal ions detection, considering that the calibration curve is almost identical, demonstrating the need to find novel strategies for improving the discrimination between $\mathrm{Cu}$ and $\mathrm{Zn}$. Although the concentration of these toxic metals was determined using a sensor immersed in water simulating the in situ monitoring, it is important to obtain a higher selectivity, considering that $\mathrm{Zn}$ and $\mathrm{Cu}$ have different toxicities in the environment.

The uncoated planar sensors used in this paper, specifically eight-pair gold IDE on PTFE substrates, have been shown to be able to distinguish changes in the cell concentration of Tetraselmis suecica (Moejes et al. 2018) at $4 \mathrm{GHz}$, and changes in $\mathrm{Pb}$ ions, detected at $2.5 \mathrm{GHz}$ (Frau et al. 2018a). However, this sensing structure alone is not reliable for distinguishing such similar pollutants in water as $\mathrm{Cu}$ and $\mathrm{Zn}$.

\section{L-CyChBCZ coatings, standard addition method and field samples}

More complex solutions were spiked using the standard addition method for evaluating the feasibility of using microwave rotational spectroscopy in the real environment by spiking a freshwater sample (FA) with $\mathrm{Cu}$ in the same manner as described in section Adapted standard addition method. These solutions were analysed using uncoated and coated gold IDE sensors with L-CyChBCZ-based films, for dipping in water.

\section{Uncoated and coated sensors: a comparison}

FA samples ( $\mathrm{Cu}$-free) processed with the standard addition method were analysed using (i) uncoated and (ii) screenprinted f-EM sensors, based on L-CyChBCZ film, and the
ZVA24. Their spectra are shown in Fig. 4a, b, respectively. The solid pink arrows (Fig. 4b) show the shift in spectral response through a higher frequency compared with Fig. 4a; the dashed violet arrows show how the spectrum changed due to the coating. Notably, the significant peaks that were identified at frequencies $<1 \mathrm{GHz}$, which reflect the changes in the reflection coefficient magnitude using the uncoated sensors, were shifted to higher frequencies. Namely, the peaks highlighted in Fig. 4a at 440 and $760 \mathrm{MHz}$ shifted to $470 \mathrm{MHz}$ and $0.92-1.00 \mathrm{GHz}$.

Moreover, the peaks produced at frequencies between $0.92-1.00 \mathrm{GHz}$ and $1.8-2.3 \mathrm{GHz}$ (indicated by the dashed violet arrows in Fig. 4b) were characterised by a bigger change due to the microwave signal reflection, with a higher $\mathrm{dB}$ variation $(\Delta \mathrm{dB})$ for $\mathrm{Cu}$ concentrations. This is probably caused by (i) a change in dielectric properties caused by the interaction of the $\mathrm{Cu}$ ions with the sensing material; (ii) the thickness of the coating itself (Chen et al. 2012).

The three peaks that are identified in the frequency range 0.01-1 GHz using uncoated and functionalised sensors
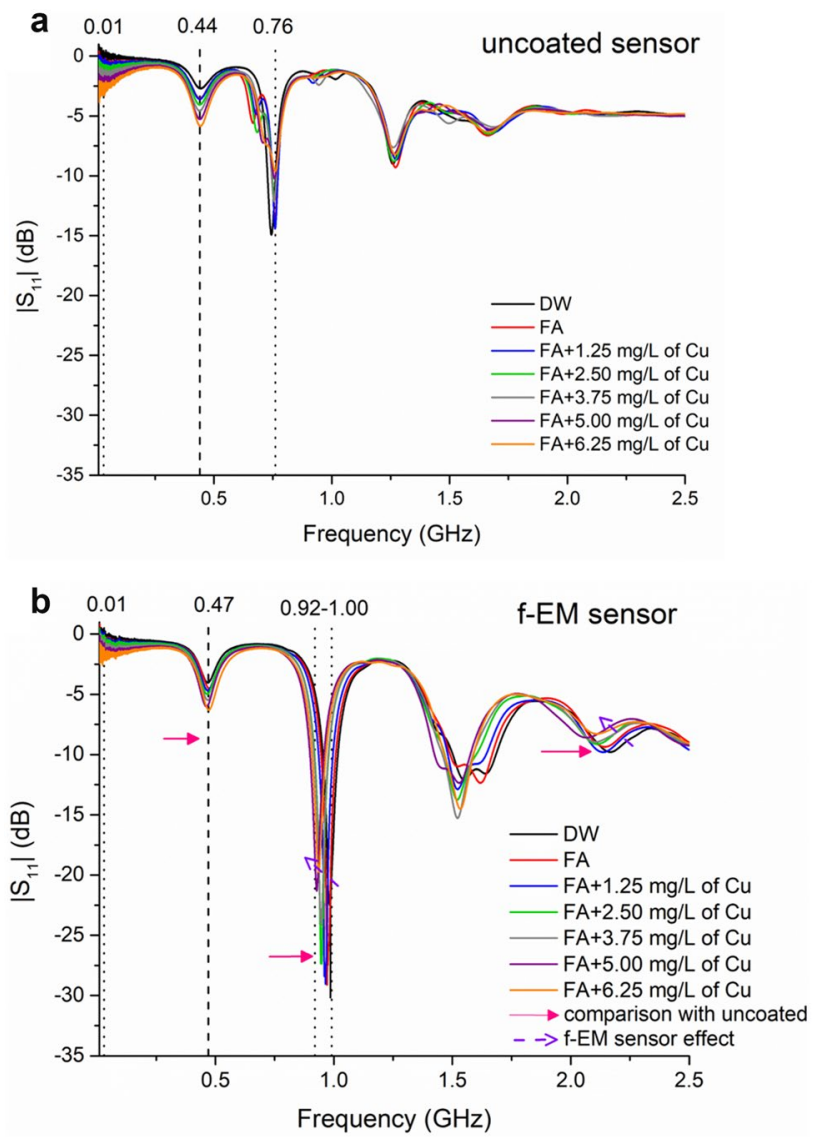

Fig. 4 a Spectral response measured using uncoated sensors and $\mathbf{b}$ f-EM sensors with L-CyChBCZ film for FA samples spiked with continual addition of $+1.25 \mathrm{mg} / \mathrm{L}$ of $\mathrm{Cu}$ concentration and comparisons with Fig. 3a (solid pink arrows) and the effect of the coating (dashed violet arrows) 
highlighted in Fig. 4a, b with dash vertical lines, pink and purple, respectively, are named as peaks 0,1 and 2 . The comparison between the sensing performances of the uncoated and coated sensors, for $\mathrm{Cu}$ concentration changes in spiked mine water samples by analysing these peaks, is summarised in Table 2. For each sensor and peak were found the $R^{2}$, the $\mathrm{CV}$, the sensitivity, the LOD and the Q-factor (described in section Reflection coefficient). The linearity of the sensing responses, sensor sensitivity and a high Q-factor are important factors for considering the sensing efficiency, as well as its combination with shifts in resonant frequency (Benkhaoua et al. 2016). The Q-factor for peak 0 at $10 \mathrm{MHz}$ cannot be evaluated, as it is represented only the "extremity" of the peak. All these parameters can be improved by considering multiple resonant peaks in the spectral response of a f-EM sensor and between f-EM sensors based on diverse functional materials.

The linearity for peak 0 was higher $\left(R^{2}=0.97\right)$ using the uncoated sensor. Also, the sensitivity (indicated by a steeper gradient) and Q-factor for both peaks 0 and 1 are higher using the uncoated sensors, with a smaller coefficient of variation and LOD compared with the f-EM sensors. However, the efficacy of the f-EM sensor at peak 2 (highlighted in bold in Table 2) is much higher compared with the uncoated sensor, with a higher linearity $\left(R^{2}=0.98\right)$, sensitivity $(1.651 \mathrm{~dB}$ changes for each $\mathrm{mg} / \mathrm{L}$ change in $\mathrm{Cu}$ concentration) and Q-factor (135.5). Moreover, the low LOD $(0.036 \mathrm{mg} / \mathrm{L})$ demonstrates the prospect of detecting the $\mathrm{Cu}$ concentration in mine water just above the EQS established as the "safe limit" in freshwater $(28-34 \mu \mathrm{g} / \mathrm{L})$. Consequently, to obtain more precise measurements, to benefit from the good performance of each selected peak and to a more specific peak characterisation, can be advantageous to perform a multipeak analysis.

\section{Lorentzian peak fitting function}

For a closer spectral analysis of the samples under test, it is interesting to consider the entire spectrum. The combined response of multiple peaks allows "pattern recognition" for a specific pollutant, with an improvement in specificity. To accomplish this, spectra responses were fitted using the Lorentzian function, as described in section Curve fitting function. An example is illustrated in Fig. 5, specifically for the sample $\mathrm{FA}+1.25 \mathrm{mg} / \mathrm{L}$ of $\mathrm{Cu}$. The multipeak analysis was performed, and the electromagnetic patterns were identified for all samples.

Six distinct peaks were identified for each sample. $\Delta S_{11}$ that is related to the small change in response at $0.01 \mathrm{GHz}$ is considered "peak 0 " as it is not a wide-ranging peak, and it was not possible to analyse all its features. Through this novel strategy it is possible to not only identify and characterise all the peaks, including those that overlapped (e.g. peaks 3, 4 and 5, Fig. 5), but also to investigate more parameters than just the centre of the peak (xc) and its intensity $(\mathrm{H})$, such as full width at half maximum $(w)$ and the area of the peak (A). The fitting function converged and a Chisquare tolerance value of $1 \times 10^{-6}$ was obtained.

Notably, the convoluted peak between 1.25 and $1.80 \mathrm{GHz}$ encloses three distinct peaks which makes the apparent peak look irregular. Overlapping of individual peaks is common in vibrational spectroscopy such as middle infrared and Raman frequencies (Meier 2005). For microwave spectroscopy and f-EM planar IDE sensors this "phenomenon" mostly occurs at frequencies higher than $1 \mathrm{GHz}$.

The obtained parameters using the Lorentz function are plotted in the scatter graphs in Fig. 6. The most interesting data in terms of higher specificity for diverse $\mathrm{Cu}$ concentrations are highlighted with orange dotted circles. From the peak centre (xc) graph (Fig. 6a), it is noted that some resonant peaks (peaks 2 and 6) are shifted to lower frequencies as the $\mathrm{Cu}$ concentration increases. Resonant frequency shifts combined with changes in other parameters enable the identification of $\mathrm{Cu}$ concentration in water at specific frequencies with improved specificity. This is related to the change in permittivity, especially at low frequency, due to the small size of the sensor (Benkhaoua et al. 2016). However, this is not valid for each peak, as only the shift of xc at peaks 2 and 6 appears to be linearly related to $\mathrm{Cu}$ concentrations.

FWHM, A and $\mathrm{H}$ present similar behaviours for the 6 peaks (Fig. 6b-d). Notably, peak 5, which was part of the convoluted peak, was not distinguished for concentrations of $\mathrm{Cu}$ higher than $+5 \mathrm{mg} / \mathrm{L}$. Particularly, it is interesting as the values decrease for peak 1 located at $0.47 \mathrm{GHz}$ when the $\mathrm{Cu}$ concentration increases and increase for peak $2(0.92-1.00 \mathrm{GHz})$. Hence, peaks 2 and 6 drift to lower

Table 2 Summary of statistical information for 3 identified peaks (at frequency $<1 \mathrm{GHz}$ ) using uncoated (UNC) and f-EM sensors based on L-CyCHBCZ for a mine water sample (Frongoch Adit, FA) spiked with $\mathrm{Cu}$ using the standard addition method

\begin{tabular}{|c|c|c|c|c|c|c|c|c|c|c|}
\hline & \multicolumn{2}{|l|}{$R^{2}$} & \multicolumn{2}{|c|}{$\mathrm{CV}(\mathrm{dB})$} & \multicolumn{2}{|c|}{ Sensitivity $(\Delta \mathrm{dB} / \mathrm{mg} / \mathrm{L})$} & \multicolumn{2}{|c|}{$\operatorname{LOD}(3)(\mathrm{mg} / \mathrm{L})$} & \multicolumn{2}{|c|}{ Q-factor(4) } \\
\hline & UNC & f-EM & UNC & f-EM & UNC & f-EM & UNC & f-EM & UNC & f-EM \\
\hline Peak 0 & 0.970 & 0.928 & 0.20 & 0.25 & 0.362 & 0.222 & 0.194 & 0.379 & I & I \\
\hline Peak 1 & 0.963 & 0.981 & 0.02 & 0.03 & 0.354 & 0.260 & 0.146 & 0.409 & 2.60 & 6.57 \\
\hline Peak 2 & 0.888 & 0.983 & 0.01 & 0.02 & 0.824 & 1.651 & 0.083 & 0.036 & 30.71 & 135.48 \\
\hline
\end{tabular}


Fig. 5 Example of the Lorentzian peak fitting function for the sample "FA $+1.25 \mathrm{mg} / \mathrm{L}$ of $\mathrm{Cu}$ " showing an example of overlapped peaks
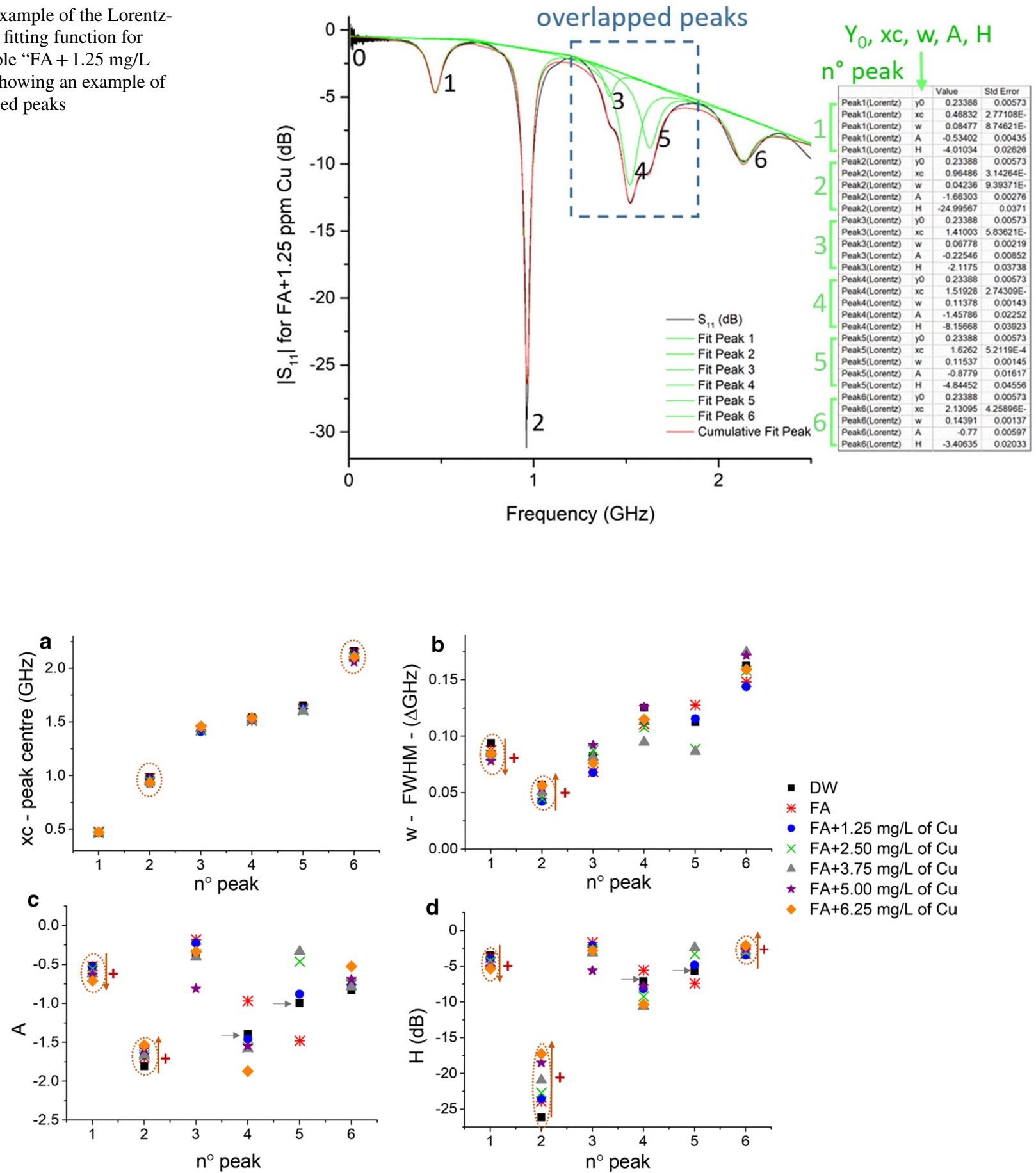

Fig. 6 Summary of peak parameters for Frongoch Adit sample spiked with the standard addition method, as a peak centre, b FWHM, c area and $\mathbf{d}$ height of the peaks determined by fitting the spectral responses with Lorentzian function with underlined points using orange dotted circles, orange and grey arrows 
frequency and decrease the $\left|S_{11}\right|$ value when the $\mathrm{Cu}$ concentration increases. The analysis of the various parameters measured for DW (grey arrows show some example), compared with the FA samples and its $\mathrm{Cu}$ additions, will help to identify the changes in spectral response that are related to the matrix composition.

\section{Cu vs Zn}

Inaccuracy of the sensing performance can be caused by the matrix of the sample and/or by the presence of other similar elements, ions or metals, which are detected at the same frequencies with the uncoated sensors and are likely to interact with the chelating polymers. Consequently, DW solutions spiked with $\mathrm{Cu}, \mathrm{Zn}$ and both $(1: 1)$ were compared. The peaks were identified for all samples at similar frequencies (xc) with some shift for the peak that were separated in the convoluted one (peaks 3, 4 and 5). Figure 7a, b shows selected peak features $(\mathrm{w}$ and $\mathrm{H})$ which compare the response for DW samples spiked with $\mathrm{Cu}, \mathrm{Zn}, \mathrm{Cu}+\mathrm{Zn}$ and FA sample spiked with $0.2 \mathrm{mg} / \mathrm{L}$ of $\mathrm{Cu}$ and $\mathrm{Zn}$ (prepared by dilution). Peaks 1 and 2 show a good linear correlation (Fig. 7c, d) for both $\mathrm{Cu}$, $\mathrm{Zn}$ and $\mathrm{Cu}+\mathrm{Zn}$, with a higher $\left(R^{2}=0.987\right)$ for $\mathrm{Zn}$ at peak 1 and a higher $\left(R^{2}=0.983\right)$ for $\mathrm{Cu}$ at peak 2 . Although the reflection coefficient changes linearly at peaks 1 and 2 , other peaks can help to differentiate between $\mathrm{Cu}$ and $\mathrm{Zn}$. As a matter of fact, the combined peak, which includes peaks 3, 4 and 5 , present differences between the same concentrations of $\mathrm{Cu}, \mathrm{Zn}$ and $\mathrm{Cu}+\mathrm{Zn}(1: 1)$. The divergences in other parameters (e.g. w) will allow a more selective identification and quantification of the specific metal under test. For example, it is notable how the FWHM of peak 6 (Fig. 7a) was more able to distinguish smaller concentration of $\mathrm{Cu}, \mathrm{Zn}$ and both.

The results demonstrate the capability of the proposed f-EM sensor based on L-CyChBCZ for selectivity sensing potential of increasing and decreasing of $\mathrm{Cu}$ and $\mathrm{Zn}$ in mining-impacted water. The responses for similar concentrations of these two metals show high repeatability and the potential to differentiate between these two pollutants by analysing multiple peaks identified which are related to changes to metal concentration. Consequently, by combining the responses for multiple peaks and various peak parameters, the selectivity can be improved, although more data are necessary for developing mathematical functions for programmed discrimination and quantification of the toxic metals under test.

The f-EM sensors based on L-CyChBCZ were able to detect changes in $\mathrm{Cu}$ and $\mathrm{Zn}$ concentration, especially in frequencies $<2.5 \mathrm{GHz}$. The detection of $\mathrm{Cu}$ using microwaves was also demonstrated by Puangngernmak and
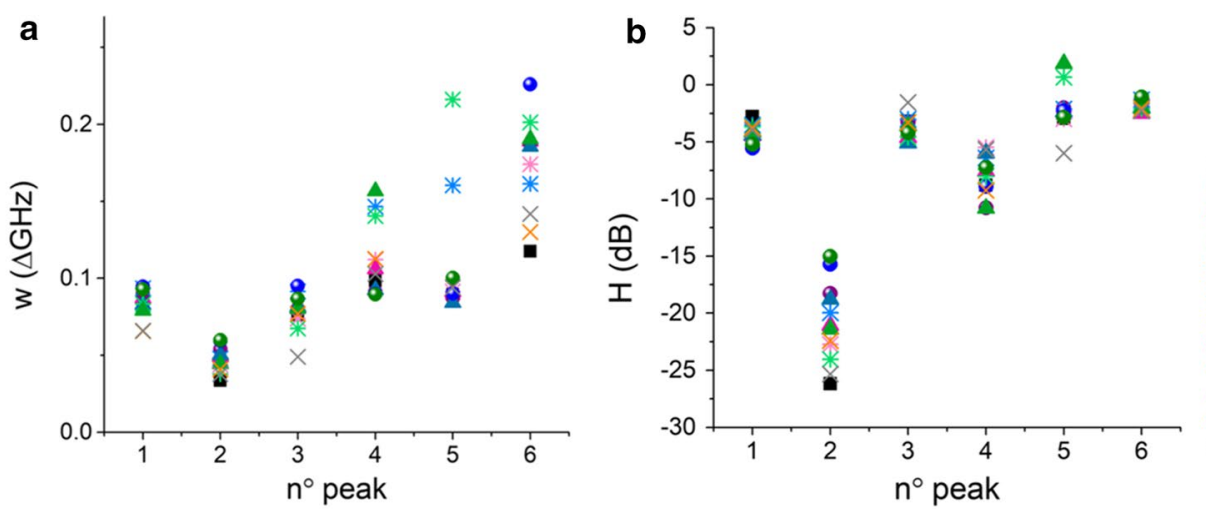

- DW

( $D W+1.25 \mathrm{mg} / \mathrm{L}$ of $\mathrm{Cu}$

- DW+2.50 mg/L of $\mathrm{Cu}$

- $\mathrm{DW}+5.00 \mathrm{mg} / \mathrm{L}$ of $\mathrm{Cu}$

* $\mathrm{DW}+1.25 \mathrm{mg} / \mathrm{L}$ of $\mathrm{Zn}$

$\Delta \quad D W+2.50 \mathrm{mg} / \mathrm{L}$ of $\mathrm{Zn}$

DW+5.00 mg/L

* $D W+1.25 \mathrm{mg} / \mathrm{L}$ of Cu\&Zn

$\triangle D W+2.50 \mathrm{mg} / \mathrm{L}$ of Cu\&Zn

- DW+5.00 mg/L of Cu\&Zn

$\mathrm{FA}+0.2 \mathrm{mg} / \mathrm{L}$ of $\mathrm{Cu}$

$\mathrm{FA}+0.2 \mathrm{mg} / \mathrm{L}$ of $\mathrm{Zn}$
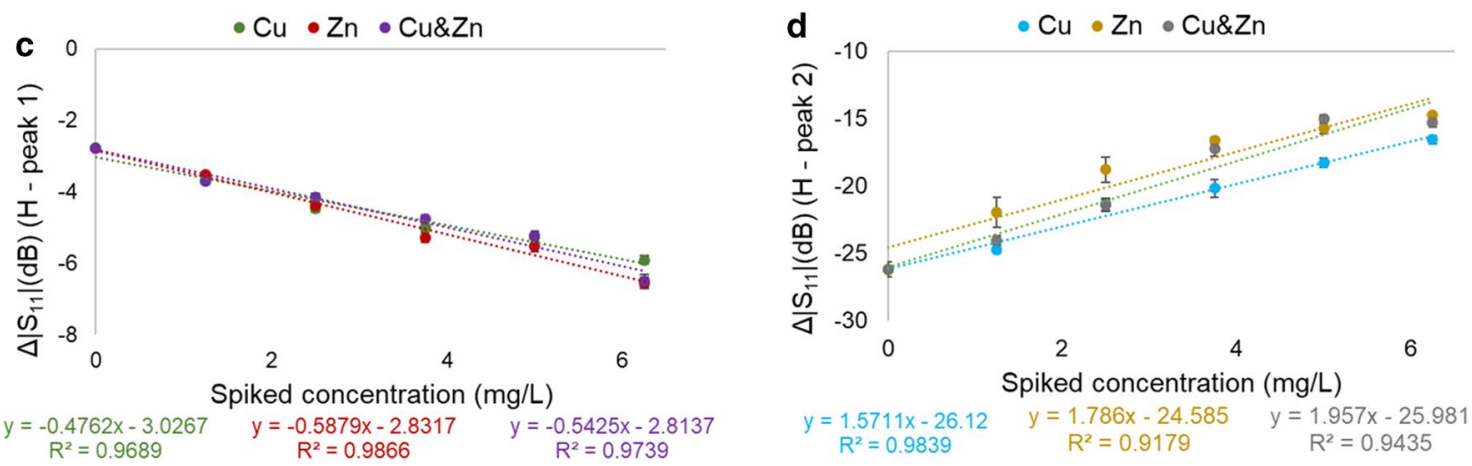

Fig. 7 Selected peak features (a w and $\mathbf{b} \mathrm{H}$ ) which show the comparison between $\mathrm{Cu}$ and $\mathrm{Zn}$ solutions; linear correlations for peaks 1 and 2 and $\mathrm{H}$ are shown in $\mathbf{c}$ and $\mathbf{d}$ 
Chalermwisutkul (2014) using an open-ended coaxial structure, to be able to distinguish only between low $(1 \mathrm{mg} / \mathrm{L})$ and very high concentrations (100 and $1000 \mathrm{mg} / \mathrm{L})$ and not changes in small concentration as is demonstrated in this paper.

\section{SEM and EDS analysis}

The interaction between $\mathrm{Cu}$ ions and the coating reached equilibrium after approximately $10 \mathrm{~min}$, as shown in Fig. 8a from the $\mathrm{S}_{11}$ measurement against time using $\mathrm{FA}+5.00 \mathrm{mg} / \mathrm{L}$ of $\mathrm{Cu}$ solution, indicating that stabilisation is reached. The presence of the copper on the sensing layer was confirmed by the SEM image (Fig. 8b) of the coating on the f-EM sensors using EDS analysis (Fig. 8d). This was expected due to the chelation with the amino and hydroxyl groups.

These changes reflect the variation in physical properties and the consequent change in complex permittivity due to the specific interaction between the $\mathrm{Cu}$ ions and the functional materials on the planar sensor, especially L-cysteine
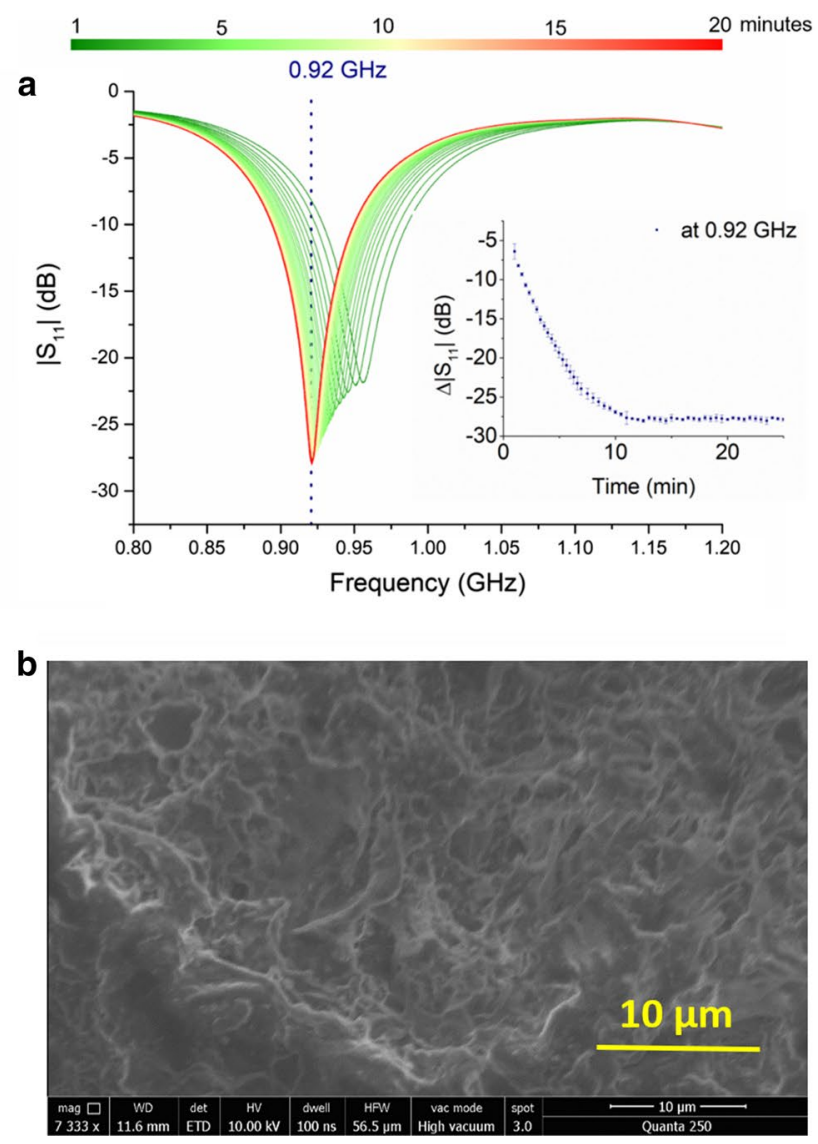

Fig. 8 a $S_{11}$ measurement by time, b scanning electron micrograph of the SEM image, $\mathbf{c}$ the recovery time of the sensor after washed returning to its baseline level and $\mathbf{d}$ EDS analysis showing the weight and chitosan that chelate with $\mathrm{Cu}$ ions. Consequently, the sensing performance was improved by a modification of the spectral response and the increment of specificity (Bernou et al. 2000). Notably, the EM waves interact with each part of the sensor and the sensing response will depend on the permittivity change of each component, such as the sensor itself, the coating, the coating thickness, the chelated metal ions on the coating and the sample under test (Frau et al. 2019a). The f-EM sensors are not only detecting the metals which are chelated on the L-CyChBCZ substrate, and which generate a variation in the spectral response, but also the overall change in the sample under test. Consequently, if there is an increase or decrease in metal concentration, the sensor would rapidly detect this change, despite the metals which chelate with the coating material.

The f-EM sensors demonstrated in this work seem to be reusable and recoverable. After washing, the f-EM returns to its baseline spectrum (defined as air spectrum) in less than 2 min (Fig. 8c). However, the SEM used was not sensitive enough for quantitatively determining the $\mathrm{Cu}$ concentration in the coatings as a function of the concentration of the
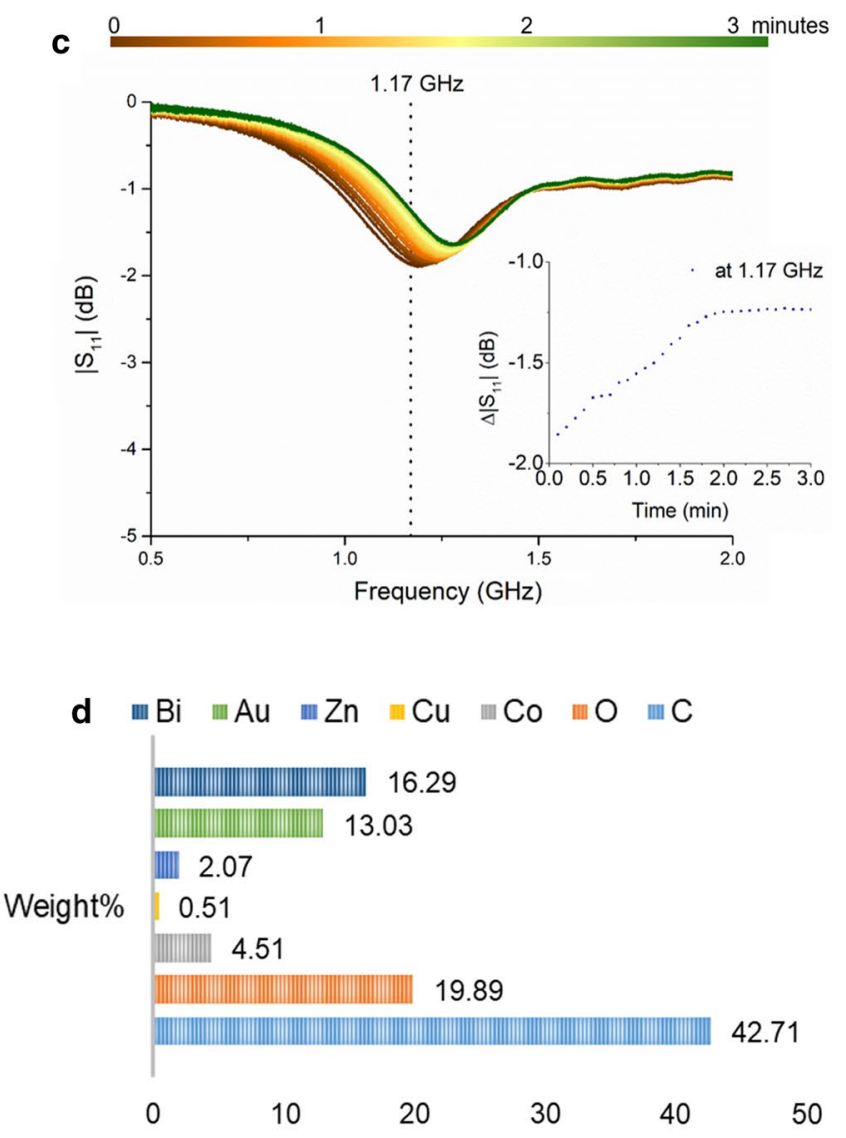

percentage of the elemental composition of the L-CyChBCZ coating after the interaction with a $\mathrm{Cu}$ solution, on the IDE 
sample or characterising the effective interaction between the sample and the materials. The $\mathrm{Zn}$ was also part of the coating materials, so it was difficult to quantify. Further work will be required using more sensitive techniques, such as X-ray photoelectron spectroscopy (XPS) analysis.

\section{Feasibility of differentiating mining-water samples}

The samples FA, MR, NC and PM, collected and named as described in section Water Samples, were measured using f-EM sensors based on L-CyChBCZ coatings. The metal concentrations, $\mathrm{pH}$ and conductivity of the four miningwater samples collected in the two mining area in Wales
Table 3 Metal concentrations and physicochemical parameters for the four samples collected in two mining areas in Wales (UK)

\begin{tabular}{lcccc}
\hline & $\mathrm{Cu}(\mathrm{mg} / \mathrm{L})$ & $\mathrm{Zn}(\mathrm{mg} / \mathrm{L})$ & $\mathrm{pH}$ & $\mathrm{EC}(\mu \mathrm{S} / \mathrm{cm})$ \\
\hline FA & $<0.001$ & 9.27 & 6.65 & 175.1 \\
$\mathrm{MR}$ & $<0.001$ & 5.87 & 5.94 & 89.6 \\
$\mathrm{NC}$ & $<0.001$ & 2.94 & 7.21 & 118.0 \\
PM & 9.31 & 10.5 & 2.44 & 5700 \\
\hline
\end{tabular}

were analysed using an ICP-MS, and EC and $\mathrm{pH}$ probes are described in Table 3 . The samples were analysed at a constant temperature $\left(18.5^{\circ} \mathrm{C}\right)$.
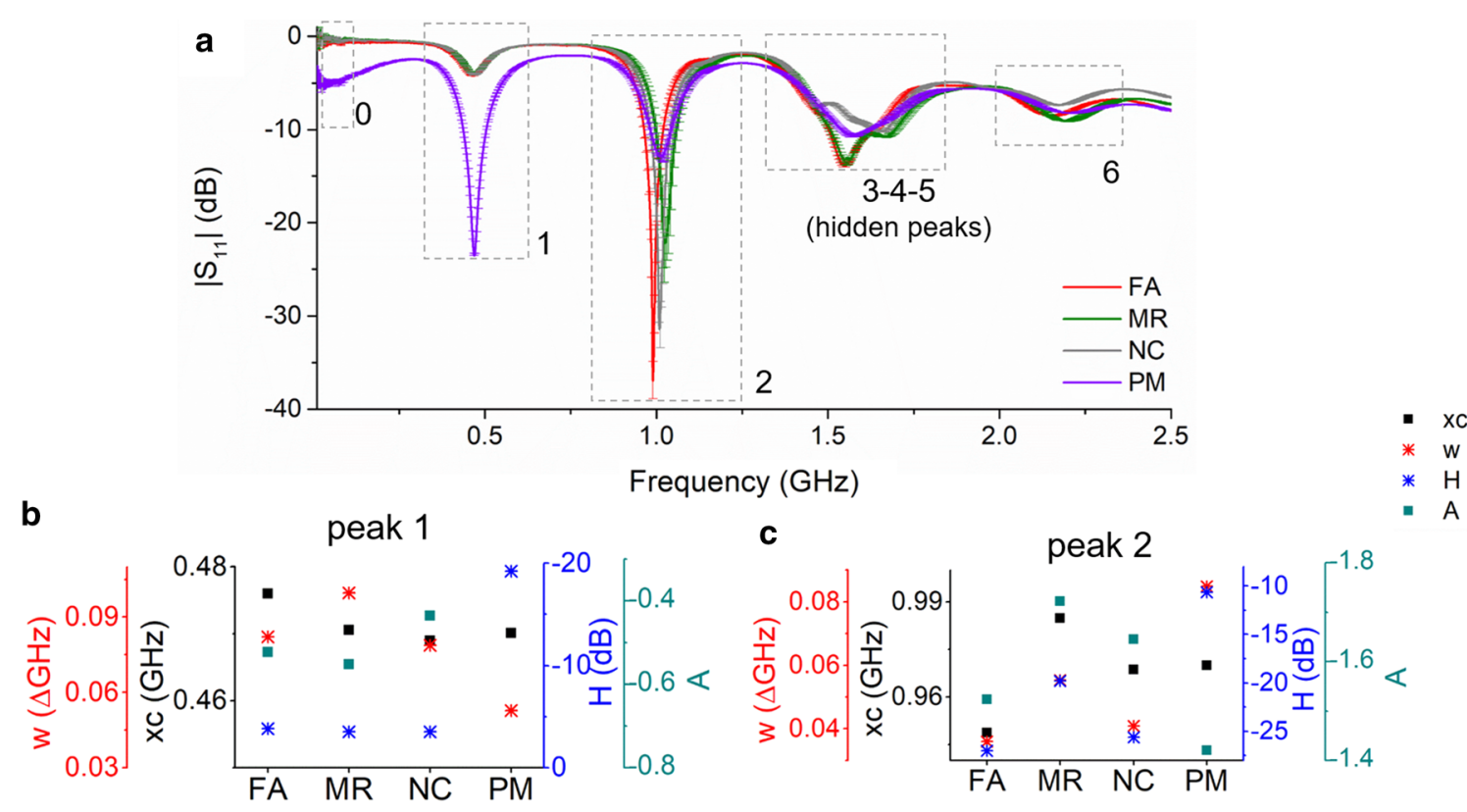

d
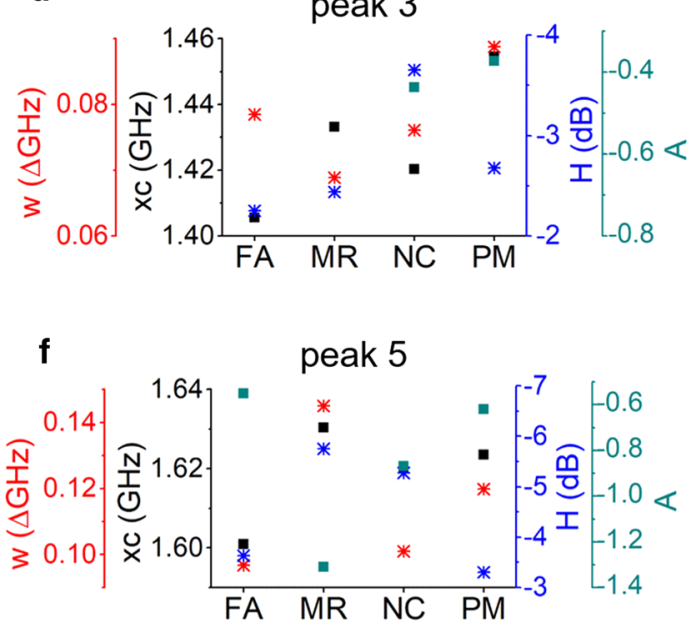

C

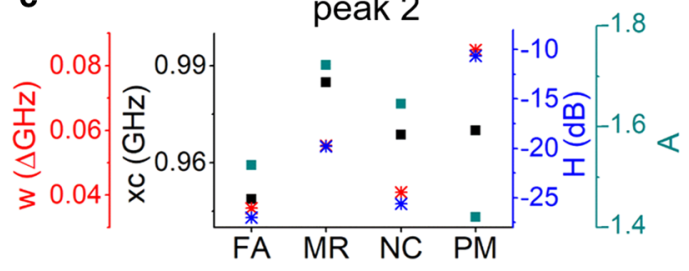

e
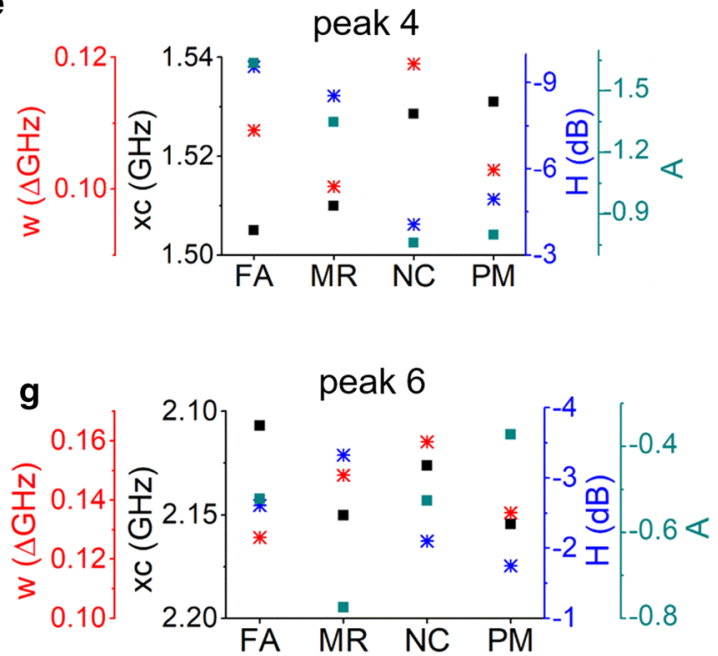

Fig. 9 a Real-mine water samples output analysed using f-EM sensors based on L-CyChBCZ-based coatings and their peak properties comparison at b peaks 1, c 2, d 3, e 4, f 5 and $\mathbf{g} 6$ 
Their spectral responses with error bars are shown in Fig. 9, which shows high repeatability with a $\mathrm{CV}<0.05 \mathrm{~dB}$ for all the measurements. Six peaks were identified for each sample, which corresponds with the location (xc) of the peaks identified for the laboratory-prepared solutions. Some minor shifts were noticed and can likely be attributed to interference caused by the diverse water matrix. Peaks 0 , 1 and 2 reflect the same general spectral behaviour identified for the FA sample series (Fig. 9 a), with major peaks which change with sample composition that are identified at $0.01-0.05,0.44-0.47$ and $0.92-1.00 \mathrm{GHz}$. A lower $\left|\mathrm{S}_{11}\right|$ value for peaks 0 and 1 should reflect a higher $\mathrm{Cu}$ and $\mathrm{Zn}$ concentration, while for peak 2 , a higher value corresponds to a higher concentration. That was perfectly reflected by the peaks located at $<1 \mathrm{GHz}$ for the PM samples, where the $\mathrm{Cu}$ contamination is a severe problem (Dean et al. 2013). The Lorentz peak fitting function and the peak features are shown in Fig. 9 b, c, d, e, f, g for peaks 0, 1, 2, 3, 4, 5 and 6.

The calibration equation obtained in section $\mathrm{Cu} v \mathrm{Zn}$ was tested using real water samples. Results show that peaks 1 and 2 can differentiate the pollution level, such as which sample is more or less polluted, but more data integration is necessary for a more specific quantification and qualification of toxic metals in mining-impacted waters. Specifically, FA shows $\mathrm{Cu}$ concentration of $1.13 \mathrm{mg} / \mathrm{L}$ and $1.21 \mathrm{mg} / \mathrm{L}$ at peaks 1 and 2, respectively; MR shows 1.05 and $3.8 \mathrm{mg} / \mathrm{L}$ of $\mathrm{Cu}$ at peaks 1 and 2; NR shows 1.04 and $0.22 \mathrm{mg} / \mathrm{L}$ of $\mathrm{Cu}$ at the same peaks; and PM shows 34.0 and $10.2 \mathrm{mg} / \mathrm{L}$. The concentration of $\mathrm{Zn}$ was quantified at peaks 1 and 2, respectively, at each sample as follows: for FA 1.2 and $1.4 \mathrm{mg} / \mathrm{L}$; for MR 1.2 and $2.7 \mathrm{mg} / \mathrm{L}$; for NC 1.2 and $0.6 \mathrm{mg} / \mathrm{L}$; and for PM 27.9 and $7.8 \mathrm{mg} / \mathrm{L}$. Although the measured concentrations were not specific, the sensors were able to qualify the pollution level, as is notable comparing results with Table 3 . This is because the linear correlation for $\mathrm{Cu}, \mathrm{Zn}$ and $\mathrm{Cu}+\mathrm{Zn}$ at peaks 1 and 2 is comparable; thus, they can interfere with each other. Even if the microwave spectrum generated by F-EM sensors which interact $\mathrm{Cu}$ and $\mathrm{Zn}$ samples is different in distinct parts of the EM spectrum, it is not sufficient to remove completely the interference generated by similar metals, such as $\mathrm{Cu}$ and $\mathrm{Zn}$. Consequently, integrating more parameters at different peaks (3-6) can give the opportunity to improve the selective detection. Moreover, some other interferences were identified, which could be due to other materials dissolved in the mining-impacted waters.

This novel approach needs further investigation to understand the causes of every interference caused by the water matrix, and more data could give an opportunity to develop f-EM sensors for specific toxic metal detection.

\section{Future challenges}

Additional work is required to evaluate and correlate changes with the water composition to further understand the effect of real water samples on the coating and its interaction with the $\mathrm{Cu}$ and $\mathrm{Zn}$ ions. Particularly, it will be necessary i) to evaluate the different microwave response for free and complexed metals, ii) to qualify and quantify the interference in the spectral response due to other inorganic and/or organic material in water, iii) to measure and correct changes caused by temperature variations. More experiments and data are also necessary for integrated peak features on the linear correlation between metal ions and the reflection coefficient.

Multianalysis will also be performed using a combination of f-EM sensors based on different coating materials. The durability and degradability of the coating integrated onto the sensor also require further research. Finally, a sensing platform made by printed microwave circuit boards set at specific frequency ranges can be manufactured and integrated into the national network for real-time metal pollution monitoring.

\section{Conclusion}

This study demonstrates the feasibility of using microwaves and planar sensors for the analysis of $\mathrm{Cu}$ and $\mathrm{Zn}$ concentrations in water. Planar sensors immersed in water were able to quantify changes of $\mathrm{Cu}$ concentration by the standard addition method. F-EM sensors, functionalised using thick films based on chelating polymers and metal oxides, were used for improving the specificity for $\mathrm{Cu}$ ions in mine water samples that were spiked continuously. The coated sensors show an improvement for $\mathrm{Cu}$ ion detection, especially in the frequency range $0.92-1.00 \mathrm{GHz}$ with an improvement in sensitivity (1.631 $\Delta \mathrm{dB} / \mathrm{mg} / \mathrm{L})$, higher Q-factor (135.5) and low LOD $(0.036 \mathrm{mg} / \mathrm{L})$, demonstrating the feasibility to detect $\mathrm{Cu}$ concentration just above the environmental quality standards for freshwater $(28-34 \mu \mathrm{g} / \mathrm{L})$. A Lorentzian peak fitting was used for analysing the spectral response to identify the parameters of the peaks, particularly those that are superimposed upon one another, including area and FWHM of the peaks. Detecting small changes in the spectral response by analysing more parameters for each peak as described was shown to improve the selectivity between $\mathrm{Cu}$ and $\mathrm{Zn}$. More work is necessary for qualifying and quantifying the interferences caused by complex water matrices and similar pollutants. This research approach could provide a reliable specific f-EM sensor array for efficient water quality monitoring. 
Acknowledgements The authors gratefully acknowledge the support of Liverpool John Moores University, the Faculty of Engineering and Technology in conjunction with the Faculty of Science PhD Scholarship Programme which allowed this research to be undertaken. Special thanks go to Prof David Phipps, Emeritus Professor, at LJMU, for his valuable suggestions, and to Patrizia Onnis, PhD researcher, at LJMU, for her support during sample collection.

\section{Compliance with ethical standards}

Conflict of interest The authors declare no conflict of interest.

Open Access This article is distributed under the terms of the Creative Commons Attribution 4.0 International License (http://creativeco mmons.org/licenses/by/4.0/), which permits unrestricted use, distribution, and reproduction in any medium, provided you give appropriate credit to the original author(s) and the source, provide a link to the Creative Commons license, and indicate if changes were made.

\section{References}

Agency for Toxic Substances and Disease Registry (ATSDR) (2004) Toxicological profile for Copper. Department of Health and Human Services, Public Health Service, Atlanta, GA

Al-Kizwini MA, Wylie SR, Al-Khafaji DA, Al-Shamma'a AI (2013) The monitoring of the two phase flow-annular flow type regime using microwave sensor technique. Measurement 46:45-51. https ://doi.org/10.1016/j.measurement.2012.05.012

Andria G, Attivissimo F, Di Nisio A, Trotta A, Camporeale SM, Pappalardi P (2019) Design of a microwave sensor for measurement of water in fuel contamination. Measurement 136:74-81. https:// doi.org/10.1016/j.measurement.2018.12.076

Ateeq M, Shaw A, Garrett R, Dickson P (2017) A proof of concept study on utilising a non-invasive microwave analysis technique to characterise silver based materials in aqueous solution. Sens Imaging 18:13. https://doi.org/10.1007/s11220-017-0162-y

Azmi A, Azman AA, Kaman KK, Ibrahim S, Mukhopadhyay SC, Nawawi SW, Yunus MAM (2017) Performance of coating materials on planar electromagnetic sensing array to detect water contamination. IEEE Sens J 17:5244-5251. https://doi.org/10.1109/ JSEN.2017.2720701

Bader M (1980) A systematic approach to standard addition methods in instrumental analysis. J Chem Educ 57:703. https://doi. org/10.1021/ed057p703

Bansod B, Kumar T, Thakur R, Rana S, Singh I (2017) A review on various electrochemical techniques for heavy metal ions detection with different sensing platforms. Biosens Bioelectron 94:443-455. https://doi.org/10.1016/j.bios.2017.03.031

Barton J et al (2016) Screen-printed electrodes for environmental monitoring of heavy metal ions: a review. Microchim Acta 183:503517. https://doi.org/10.1007/s00604-015-1651-0

Benkhaoua L, Benhabiles MT, Mouissat S, Riabi ML (2016) Miniaturized quasi-lumped resonator for dielectric characterization of liquid mixtures. IEEE Sens J 16:1603-1610. https://doi.org/10.1109/ JSEN.2015.2504601

Bernou C, Rebière D, Pistré J (2000) Microwave sensors: a new sensing principle. Application to humidity detection. Sens Actuators B Chem 68:88-93. https://doi.org/10.1016/S0925-4005(00)00466-4

Bruce GR, Gill PS (1999) Estimates of precision in a standard additions analysis. J Chem Educ 76:805. https://doi.org/10.1021/ed076p805

Byrne P, Wood PJ, Reid I (2012) The impairment of river systems by metal mine contamination: a review including remediation options. Crit Rev Environ Sci Technol 42:2017-2077. https:// doi.org/10.1080/10643389.2011.574103

Byrne P, Hudson-Edwards KA, Bird G, Macklin MG, Brewer PA, Williams RD, Jamieson HE (2018) Water quality impacts and river system recovery following the 2014 Mount Polley mine tailings dam spill. British Columbia. Can Appl Geochem 91:64-74. https ://doi.org/10.1016/j.apgeochem.2018.01.012

Cases-Utrera J, Escudé-Pujol R, Ibáñez-Otazua N, Javier del Campo F (2015) Development of an automated heavy metal. Anal Electroanal 27:929-937. https://doi.org/10.1002/elan.201400614

Cashman S, Korostynska O, Shaw A, Lisboa P, Conroy L (2017) Detecting the presence and concentration of nitrate in water using microwave spectroscopy. IEEE Sens J. https://doi.org/10.1109/ jsen.2017.2705281

Chen T, Li S, Sun H (2012) Metamaterials application in sensing. Sensors 12:2742

Dean AP, Lynch S, Rowland P, Toft BD, Pittman JK, White KN (2013) Natural wetlands are efficient at providing long-term metal remediation of freshwater systems polluted by acid mine drainage. Environ Sci Technol 47:12029-12036. https://doi.org/10.1021/ es4025904

Ebrahimi A, Withayachumnankul W, Al-Sarawi S, Abbott D (2014) High-sensitivity metamaterial-inspired sensor for microfluidic dielectric characterization. IEEE Sens J 14:1345-1351. https:// doi.org/10.1109/JSEN.2013.2295312

Environment Agency (2008) Abandoned mines and the water environment vol Science project SC030136. Environment Agency, Bristol

Environment Agency (2012) Prioritisation of abandoned non-coal mine impacts on the environment vol SC030136/R2 The national picture. Environment Agency, Bristol

Frau I, Korostynska O, Mason A, Byrne P (2018a) Comparison of electromagnetic wave sensors with optical and low-frequency spectroscopy methods for real-time monitoring of lead concentrations in mine water. Mine Water Environ. https://doi.org/10.1007/ s10230-018-0511-7

Frau I, Wylie S, Byrne P, Cullen J, Korostynska O, Mason A (2018b) Continuous detection of copper and bromide in polluted water using f-EM sensors. In: 2018 12th international conference on sensing technology (ICST), pp 35-38. https://doi.org/10.1109/ icsenst.2018.8603592

Frau I, Wylie S, Byrne P, Cullen J, Korostynska O, Mason A (2019a) Detection of $\mathrm{Zn}$ in water using novel functionalised planar microwave sensors. Mater Sci Eng, B 247:114382. https://doi. org/10.1016/j.mseb.2019.114382

Frau I, Wylie S, Cullen J, Korostynska O, Byrne P, Mason A (2019b) Microwaves and functional materials: a novel method to continuously detect metal ions in water. In: Mukhopadhyay SC, Jayasundera KP, Postolache OA (eds) Modern sensing technologies. Springer, Cham, pp 179-201. https://doi.org/10.1016/j. mseb.2019.114382

Graunke T, Schmitt K, Busch S, Raible S, Wöllenstein J (2018) Towards an empirical model for the prediction of the selectivity of polymer. Membr Proc 2:979

Greene J, Abdullah B, Cullen J, Korostynska O, Louis J, Mason A (2019) Non-invasive monitoring of glycogen in real-time using an electromagnetic sensor. In: Mukhopadhyay SC, Jayasundera KP, Postolache OA (eds) Modern sensing technologies. Springer, Cham, pp 1-15. https://doi.org/10.1007/978-3-319-99540-3_1

Guo Z, Niu Q, Li T, Sun T, Chi H (2019) A fast, highly selective and sensitive colorimetric and fluorescent sensor for $\mathrm{Cu} 2+$ and its application in real water and food samples. Spectrochimica Acta Part A Mol Biomol Spectrosc. https://doi.org/10.1016/j. saa.2019.01.044

Harnsoongnoen S, Wanthong A, Charoen-In U, Siritaratiwat A (2018) Planar microwave sensor for detection and discrimination of 
aqueous organic and inorganic solutions. Sens Actuators B Chem 271:300-305. https://doi.org/10.1016/j.snb.2018.05.077

Harris DC (2007) Quantitative chemical analysis, 7th edn. W.H. Freeman, New York

Holmes J, Pathirathna P, Hashemi P (2018) Novel frontiers in voltammetric trace metal analysis: towards real time, on-site, in situ measurements. TrAC Trends Anal Chem. https://doi. org/10.1016/j.trac.2018.11.003

Iqbal J, Yiping DU, Howari F, Bataineh M, Muhammad N, Rahim A (2017) Simultaneous enrichment and on-line detection of lowconcentration copper, cobalt, and nickel ions in water by nearinfrared diffuse reflectance spectroscopy combined with chemometrics. J AOAC Int 100:560-565. https://doi.org/10.5740/jaoac int.16-0224

Jilani MT, Rehman MZU, Khan AM, Khan MT, Ali SM (2012) A brief review of measuring techniques for characterization of dielectric materials. Int J Inf Technol Electr Eng 1:1

Johnson DB (2003) Chemical and microbiological characteristics of mineral spoils and drainage waters at abandoned coal and metal mines water. Air Soil Pollut Focus 3:47-66. https://doi. org/10.1023/A:1022107520836

Kölbl F, Boulboul N, Commereuc M, Bourdel E (2018) A microstrip resonator based sensor for $\mathrm{GHz}$ characterization of in vitro cell culture. In: 2018 12th International conference on sensing technology (ICST), pp 319-323. https://doi.org/10.1109/icsen st. 2018.8603622

Koneswaran M, Narayanaswamy R (2009) 1-Cysteine-capped ZnS quantum dots based fluorescence sensor for $\mathrm{Cu} 2+$ ion. Sens Actuators B Chem 139:104-109. https://doi.org/10.1016/j. snb.2008.09.028

Kopitzke S, Geissinger P (2014) An optical fiber-based sensor array for the monitoring of zinc and copper ions in aqueous. Environ Sens 14:3077-3094. https://doi.org/10.3390/s140203077

Korostynska O, Mason A, Al-Shamma'a AI (2013) Flexible microwave sensors for real-time analysis of water contaminants. J Electromagn Waves Appl 27:2075-2089. https://doi.org/10.1080/09205 071.2013 .832393

Korostynska O, Mason A, Ortoneda-Pedrola M, Al-Shamma'a A (2014) Electromagnetic wave sensing of NO3 and COD concentrations for real-time environmental and industrial monitoring. Sens Actuators B Chem 198:49-54. https://doi.org/10.1016/j. snb.2014.03.030

Mason A et al (2016) Theoretical basis and application for measuring pork loin drip loss using microwave spectroscopy. Sensors 16:182. https://doi.org/10.3390/s16020182

Mason A et al (2018) Real-time microwave, dielectric, and optical sensing of lincomycin and tylosin antibiotics in water: sensor fusion for environmental safety. J Sens 2018:11. https://doi. org/10.1155/2018/7976105

Mayes WM, Potter HAB, Jarvis AP (2013) Riverine flux of metals from historically mined orefields in England and Wales Water, Air. Soil Pollut 224:1425. https://doi.org/10.1007/s11270-012-1425-9

Meier RJ (2005) On art and science in curve-fitting vibrational spectra. Vib Spectrosc 39:266-269. https://doi.org/10.1016/j.vibsp ec.2005.03.003

Moejes K, Sherif R, Dürr S, Conlan S, Mason A, Korostynska O (2018) Real-time monitoring of tetraselmis suecica in a saline environment as means of early water pollution detection. Toxics 6:57

Nag A, Alahi MEE, Feng S, Mukhopadhyay SC (2019) IoT-based sensing system for phosphate detection using Graphite/PDMS sensors. Sens Actuators A 286:43-50. https://doi.org/10.1016/j. sna.2018.12.020

National Academies of Sciences E, Medicine (2018) Future water priorities for the nation: directions for the U.S. geological survey water mission area. The National Academies Press, Washington, DC. https://doi.org/10.17226/25134
Ngah WSW, Fatinathan S (2008) Adsorption of $\mathrm{Cu}(\mathrm{II})$ ions in aqueous solution using chitosan beads, chitosan-GLA beads and chitosanalginate beads. Chem Eng J 143:62-72. https://doi.org/10.1016/j. cej.2007.12.006

Onnis P, Byrne P, Hudson-Edwards KA, Stott T, Hunt C (2018) Source apportionment of trace metals over a range of stream flows using a multi-method tracer approach. In: Wolkersdorfer C, Sartz L, Weber A, Burgess J, Tremblay G (eds) 11th ICARD I IMWA । MWD Conference-“Risk to Opportunity", Pretoria, South Africa, Tshwane University of Technology, pp 843-849

Perkins WT, Bird G, Jacobs SR, Devoy C (2016) Field-scale study of the influence of differing remediation strategies on trace metal geochemistry in metal mine tailings from the Irish Midlands. Environ Sci Pollut Res 23:5592-5608. https://doi.org/10.1007/ s11356-015-5725-7

Prudenziati M, Hormadaly J (2012) 1-Technologies for printed films. In: Prudenziati M, Hormadaly J (eds) Printed films. Woodhead Publishing, Cambridge, pp 3-29. https://doi.org/10.1533/97808 57096210.1.3

Puangngernmak N, Chalermwisutkul S (2014) Characterization of heavy metal contaminated wastewater using a coaxial sensor and electromagnetic wave reflection technique. Appl Mech Mater 548-549:678-682

Rahman NA, Zakaria Z, Rahim RA, Dasril Y, Mohd Bahar AA (2017) Planar microwave sensors for accurate measurement of material characterization: a review. TELKOMNIKA 15:1108-1118. https ://doi.org/10.12928/TELKOMNIKA.6684

Rahman MM, Alam MM, Asiri AM (2018) Sensitive 1,2-dichlorobenzene chemi-sensor development based on solvothermally prepared $\mathrm{FeO} / \mathrm{CdO}$ nanocubes for environmental safety. J Ind Eng Chem 62:392-400. https://doi.org/10.1016/j.jiec.2018.01.019

Salim A, Lim S (2018) Review of recent metamaterial microfluidic sensors. Sensors 18:232

Salim A, Memon M, Lim S (2018) Simultaneous detection of two chemicals using a TE20-mode substrate-integrated waveguide resonator. Sensors 18:811

Shukla A, Srivastava S, D'Souza SF (2018) An integrative approach toward biosensing and bioremediation of metals and metalloids. Int J Environ Sci Technol 15:2701-2712. https://doi.org/10.1007/ s13762-018-1766-Z

Tan L et al (2016) Dual channel sensor for detection and discrimination of heavy metal ions based on colorimetric and fluorescence response of the AuNPs-DNA conjugates. Biosens Bioelectron 85:414-421. https://doi.org/10.1016/j.bios.2016.05.038

Ugwu I, Igbokwe O (2019) Sorption of heavy metals on clay minerals and oxides: a review. https://doi.org/10.5772/intechopen.80989

UK Technical Advisory Group on the Water Framework Directive (2008) UK environmental standards and conditions (phase 1-SR1-2006)

United States Environmental Protection Agency (1986) Quality criteria for water, vol 440. EPA, Washington, DC, p 20460

Varun S, Daniel SCGK (2018) Emerging nanosensing strategies for heavy metal detection. Nanotechnol Sustain Water Resour. https ://doi.org/10.1002/9781119323655.ch7

Wang L (2018) Microwave sensors for breast cancer detection. Sensors 18:165. https://doi.org/10.3390/s18020655

Wei Z, Huang J, Li J, Xu G, Ju Z, Liu X, Ni X (2018) A high-sensitivity microfluidic sensor based on a substrate integrated waveguide reentrant cavity for complex permittivity measurement of liquids. Sensors 18:4005

Wiltshire BD, Zarifi MH (2018) 3D printing microfluidic channels with embedded planar microwave resonators for RFID and liquid detection. IEEE Microw Wirel Compon Lett 29(1):65-67

Wolkersdorfer C (2008) Water management at abandoned flooded underground mines - fundamentals, tracer tests, modelling, water treatment. Springer, Heidelberg 
$\mathrm{Wu}$ W et al (2019) Simultaneous voltammetric determination of cadmium(II), lead(II), mercury(II), zinc(II), and copper(II) using a glassy carbon electrode modified with magnetite (Fe3O4) nanoparticles and fluorinated multiwalled carbon nanotubes. Microchimica Acta 186:97. https://doi.org/10.1007/s00604-018-3216-5

Xie G-L, Yu H, Deng M-H, Zhao X-L, Yu P (2019) A colorimetric microfluidic sensor made by a simple instrumental-free prototyping process for sensitive quantitation of copper. Chem Pap. https ://doi.org/10.1007/s11696-019-00702-3

Younger PL, Banwart SA, Hedin RS (2002) Hydrology, pollution, remediation. Kluwer Academic Publishers, Dordrecht

Zarifi MH, Daneshmand M (2016) Liquid sensing in aquatic environment using high quality planar microwave resonator. Sens
Actuators B Chem 225:517-521. https://doi.org/10.1016/j. snb.2015.11.063

Zarifi MH et al (2018a) A microwave ring resonator sensor for early detection of breaches in pipeline coatings. IEEE Trans Ind Electron 65:1626-1635. https://doi.org/10.1109/TIE.2017.2733449

Zarifi MH, Gholidoust A, Abdolrazzaghi M, Shariaty P, Hashisho Z, Daneshmand M (2018b) Sensitivity enhancement in planar microwave active-resonator using metal organic framework for $\mathrm{CO} 2$ detection. Sens Actuators B Chem 255:1561-1568. https://doi. org/10.1016/j.snb.2017.08.169 